\title{
Psychosocial Correlates of Stress among International and American Students
}

\author{
Susheelabai Srinivasa ${ }^{1}$ \\ ${ }^{1}$ Ph.D., University of Texas Rio Grande Valley, United States \\ Correspondence: Susheelabai Srinivasa, Ph.D., University of Texas Rio Grande Valley, United States.
}

Received: November 6, 2021

Accepted: January 26, 2022

Available online: February 14, 2022

doi:10.11114/ijsss.v10i2.5483

URL: https://doi.org/10.11114/ijsss.v10i2.5483

\begin{abstract}
Student life in college tends to be stressful since it entails a variety of demands and challenges. Academic demands and psychosocial factors cause stress in students, besides compounding factors like personal commitments, life events, and inadequate social and economic supports in pursuing college education. This study investigated academic stress among international students $(\mathrm{N}=90)$ in comparison to American students $(\mathrm{N}=131)$ and identified the psychosocial correlates of stress using the Gadzella's SLSI. Furthermore, this study not only portrayed the characteristics of international students but also determined the predictors of stress from among factors like social support or social provision, social desirability, and general health. This study concluded that both American (domestic) and international students experience stress. American (domestic) students were found to have higher levels of stress. However, cultural factors of international students are intertwined with the perception and expression of emotions relating to stress and mental health. The study recommends that higher educational institutions should beef up support services such as counseling to deal with stress, time management, wellness and mental health, and guidance about campus support services. Further research is needed on student stress comparing these two groups.
\end{abstract}

Keywords: stress, international students, American students, psychosocial causes, college student stress and mental wellness

\section{Introduction}

The college student's life is stressful with many life-events and academic demands. International students might experience stress due to expectations of the program as well as the competitive environment in which they must strive (Essendon, 1995; Mori, 2000). Students' stress may increase with multiple roles. Family malfunctioning and life events may be major contributors to students' stress (Cheng, Leong, \& Geist, 1993). Other conditions that may present challenges and exacerbate stress for students include students' adaptation to college environment, new educational system, and the new culture (Cheng, Leong, \& Geist, 1993). A series of college-related activities, such as commuting to college, developing student-teacher relationships, meeting deadlines for academic tasks and assignments, earning good grades or ranks, obtaining educational loans and financial aid to pay tuition (Mori, 2000), and managing part-time jobs, causing stress in students' college life (Lazarus, 1966).

Culture shock is a common phenomenon among international students. According to Olberg (1960), the term "culture shock" refers to the difficulties encountered throughout the acculturation process. This might be a cause of stress for many overseas students, as adjusting to a new academic and social environment was stressful for all college students. International students' adaptation can be seen as more stressful in such environments, as they expressed concerns with cultural values, language, academic preparation, study habits, and uprooting disorders (including separation from the home environment), and life stressors were associated with academic problems as well.

Cheng, Leong, and Geist (1993) mentioned both American and international students experience stress due to life-events or any alterations in the family structure at times poses stressors to the individual. Other factors include illness, accidents, the death of a family member, job loss, childbirth, and the addition of a new family member through marriage, a relative, or extended family. Reasons such as the influence of bad behaviours, being accustomed to alcohol and drugs, overworking, and a lack of sharing and interaction among family members could all be possible sources of stress that disrupt the individuals' homeostasis and impair their lifestyle, health, and wellness. The accumulation of stress raises the likelihood of physical illness and psychological distress (Lazarus \& Folkman, 1994; Pearlin, 1999). An Individual's 
response to the stressful event(s) depends on heredity, personality, physical conditions, emotional factors, and previous experiences. Individuals who are resilient remain unaffected and adapt positively even under stressful conditions (Sarason, Pierce, \& Sarason, 1994).

\section{The Purpose of Study}

The study intends to measure stress among international college students by identifying psychosocial correlates of stress. The study will also compare international students and American students pursuing their college degrees in the United States vis-a-vis stress and correlates of stress. The study sought to examine the hypotheses falling under these objectives: i) to identify adaptation difficulties and their relationship with general health issues; ii) to determine correlates of relationship of general health, social desirability, social provisions (social support) to student-life stress and its predictors; iii) to examine the influence of certain demographic variables and their association with incidence of stress, and (iv) to explicate possible effects of stress on academic performance and implications for support services for international students.

\section{Methodology}

The study conformed to the descriptive-analytic design because it sought to portray the characteristics of international students. It also tried to establish the predictors of stress as well as deeper analysis of its proposed correlates - social provisions (social support), social desirability, general health, and demographic variables.

This research was carried out at a public university in Northwest Ohio, USA. This university was chosen because a large number of international students were well represented. Permission from the University's Institutional Review Board (IRB) to conduct human subject research was obtained. The study employed a quota sampling design with self-selection. Quotas of 60:40 American and international student groups were fixed, and respondents choose whether to take part in the survey. The sample includes both undergraduate and graduate students (221 subjects). A combined returned rate (of the surveys) of $32 \%$ was achieved in the study.

Gadzella's (1991) standardized scales were used to measure student-life stress. General Health Questionnaire (GHQ) was used to measure general health (Goldberg \& Hiller, 1979), the social provisions scale was used to measure perceived social support (Russell \& Cutrona, 1987), and the Social Desirability Scale was used to assess social desirability (Marlow-Crowne, 1992). Gadzella's SLSI (1991) scale was purchased from the author. The permission from the authors of the other scales was also obtained and these instruments were tested on a small group of 10 students. A few demographic variables were also used in the study. Data collected was analyzed for mean, standard deviation, quartile deviation, Pearson's correlation coefficient, regression, Chi-Square test and t-test to determine the bivariate relationships and establish the predictors of stress. The descriptions of all the scales are described below.

\subsection{Gadzella's Student Life Stress Inventory (SLSI, 1991)}

This study measured academic stress and reactions to stressors using the scale developed by Gadzella (SLSI, 1991). The scale consists of five dimensions of stress viz frustrations (delays, daily hassles, failures, and lack of resources), pressures (deadlines, overload, and interpersonal relationships), conflicts (having a hard time to decide between several alternatives -desirables and undesirables), changes (unpleasant, too many), self-imposed (imposing unattainable goals- competitiveness, worrying, procrastination) in daily life and frequency with which these symptoms show up in international and American students. The scale also measured reactions to stress in the domains of physiological (physiological nervousness, sweating, stuttering, getting exhausted, headaches), emotional (being afraid, anxious, anger, guilt, depression), behavioral (crying, abusing self or others, smoking, attempting suicide, separating oneself from others), and cognitive (analyzing the stressful situations and strategies used in coping with stress), which represent adaptation responses to stressful situations. The scale was found to have a Cronbach Alpha score of 0.94 which demonstrated high reliability.

The inventory is designed to help students, administrators, and the educational institutions dealing with the students to assess their stressors, identify their levels of stress, and help students to build their coping skills.

\subsection{General Health Questionnaire by Goldberg and Hiller (GHQ, 1979)}

The general health questionnaire is a self-administered questionnaire used to diagnose psychiatric disorders. The scale has 2 major sets of phenomena. The first set deals with one's inability to carry out one's normal or healthy functions and the second set of the scale deals with the appearance of new phenomena of distressing nature. These two sets of items were organized into four subscales: A deals with somatic symptoms, B with anxiety and insomnia, C with social dysfunction, and D with severe depression. Each subscale has 7 items making a total of 28 items in the GHQ. The original scale consisted of a set of 60 symptoms. Later the shorter version of the 28 items GHQ was formulated with a 0.73 Cronbach Alpha score for scale reliability. The level of assessment on this scale indicates that the subjects are likely to be perceived as sub-clinically disturbed Goldberg and Blackwell (1970). The scoring method was based on the Likert method. There are four sub-scales for the scale. 1 . The scale for somatic symptoms is on the A scale. 2. The 
reported symptom 'anxiety and worry' and 'observed anxiety' for the B scale. 3. The sum of reported 'despondency' and 'observed depressed mood' for the D scale and the sum of all the morbid ratings 'severity ratings' for the total scores. 4. The ' $\mathrm{C}$ 'scale was not validated, as a rating of social dysfunction was not made in the study.

\subsection{Social Support/Social Provisions Scale by Cutrona and Russell (1987)}

This scale measures social provisions/social support as well as studies relation between social support and health (dimensions of measures of stress and depression) across a variety of contexts including high levels of stress. The measures of this social provisions scale are based on the Weiss model (1974) of the social provisions that included six different social functions that individuals seek through relationships with others. The scale was found to have high reliability with a Cronbach score of 0.73 .

They felt that stress would be assessed on various dimensions; hence social support was viewed as a multi-dimensional construct that includes attachment, social integration, reassurances of worth, reliable alliance, guidance, and opportunity for nurturance. They found social provisions interaction was a predictor of stress along with the measures of social desirability, introversion-extroversion, and neuroticism. The social provisions scale would add to the explanation of psychological distress over and above social desirability, introversion-extroversion personality characteristic, and neuroticism.

\subsection{Marlowe-Crowne Short Version of Social Desirability Scale}

Marlowe-Crowne developed a shorter version of social desirability scale with five items. A review of several articles of the 33-item M-C social desirability was undertaken in order to establish the validity of the scale (Strahan \& Gerbasi, 1972). Three short-versions of the M-C 33 were formulated. M-C 20 scale had the internal consistency as that of the original measure. M-C 1(10) \& M-C 2 (10) item scales were recommended when there is less time for the interview. Three short-forms of Reynolds' own scales and three short-forms of Strahan and Gerbasi's scales, a total of 6 short forms of the scales, were analyzed to check the best scale for psychometric efficiency. One 13 item scale was found reliable with alpha > 0.76) and another Strahan and Gerbasi's 20- item scale with an Alpha score of $r=0.79$ ).

One of Strahan and Gerbasi's forms, and all three of it, are left to the reader's discretion to decide if form C by Reynolds with 0.80 is on par with the original M-C instrument. Zook and Sipps (1985) analyzed short forms of M-C (33) by Strahan and Gerbasi (1972) and Reynolds (1982). Attention was given specifically to the gender variable and was felt short form could be utilized without losing the reliability. Reynolds 13 item form was recommended, as it was found the best form among other forms at that given point of time. A pilot study for M-C-1 (10) and M-C-2 (10) was done to rule out the confusion of any sort among the elderly population and African American adults. Both the scales were found good. Since M-C 2 (10) was received well, hence M-C 2 (10) is recommended for use to measure social desirability.

\section{Review of Literature}

A large body of research literature exists discerning the stress experienced by college students (e.g., Edwards, Hershberger, Russell, \& Market, 2001; Misra, McKean, West, \& Russo, 2000; Reifman \& Dunkel-Schetter, 1990; Zaleski, Levey-Thors, \& Schiaffino, 1999) but research on international students is scanty.

Harris (1972) found a significant correlation between stress, life-events, and the academic performance of college students. Rajendran and Kaliappan (1991) investigated the sources of student academic stress and found that higher levels of stress were associated with relatively poor grades. Earlier studies cited below focused on the differences in stress levels and stressors between American and international students and found some of the stressors were common to both populations. Leong, Mallinckrodt, and Krali (1990) found that international students had fewer stressful events than American students. Conversely, Boyer, and Sedlack (1988) and Pederson (1991) found that international students had good academic skills but tended to face more problems than American students due to fewer resources at their disposal. Kaczmarek, Matlock, Merta, Ames, and Ross (1994) stated that international students, specifically Asians, reported increases in somatic and psychological symptoms.

Rao, Moudud, and Subbakrishna (2000) studied a sample of 258 male and female undergraduates to examine their stress levels and coping behaviors. Negative academic stressors such as failure in examinations, inter-personal stressors, and breakdowns in relationships were presented to students. They felt that they could exercise control on academic stressors but not on inter-personal stressors. They took personal responsibility for failure on examination rather than blaming "the system", their fate, or other factors beyond their control. They further felt that harm was caused to them when they failed by not adapting to situations. Mori (2000); Zwingmann and Gunn (1983) revealed that international students had pressure to achieve higher academic success and top grades/ranks. Bradley (2000) reported that some international students experienced problems making friends which lead to interpersonal tensions. Before arriving abroad for higher studies, international students felt excited but felt stressed afterward. Students refrained from sharing such 
attitudes with anyone for fear of shame and non-acceptance.

Ying, Lee, and Tsai (2004) examined the challenges faced by ethnic minority college students in the areas of cultural, academic, social, and practical aspects of college life. They developed an instrument to measure those challenges and conducted this study. The measure included several stressors (racism and cross-cultural communication difficulty, financial worry, academic demands, unclear career options, housing problems, social isolation, romantic difficulties, difficulty with academic expression, unfamiliarity with campus, inability to study, and pressure to use substances) and their association with depression. The research findings showed (1) less academically advanced students faced more academic challenges, (2) new students faced more problems to find housing, (3) students living with family members felt more isolated from campus life, (4) newer students suffered frequent sickness and sought peer support, and (5) finally, dependence on the Chinese language was associated with racism, cross-cultural communication problems, and difficulties with academic expression. Overall, students with limited English skills expressed higher stress levels, as well as a desire for counseling services.

Lewthwaite (1996) looked at the international students' study experiences and adaptation to new academic, social, cultural, and linguistic environments in New Zealand. The study revealed if cultural integration of the students did not occur in the host environment, they did not integrate themselves in their academic environment either. Additionally, international students also had difficulty in understanding the New Zealand-style of English. Aneshensel (1988) study revealed women students exhibited higher stress reactions and expressed them overtly compared to men students. Men, on the contrary, accepted the problems and thought of problem-solving behaviors with better emotional control. When men experienced stress they exhibited by getting aggressive and engaging in maladaptive behaviors such as drinking, but women often exhibited stress through depressive symptoms.

Tandon's study (1986) concluded that students who coped with life stresses without impairing their health were characterized by a more positive philosophy of life and continued to perceive life meaningfully even in suffering. Another research evidence on international students by (Berry,1985) revealed that international students experienced less stress when they were more acculturated.

\section{Current study}

Many international students come to the United States for higher education than any other country in the world (McMutrie, 2001). What is not known is if American and international students in the same institutions experience stress? If so, are students expressing stress in the same way or differently, and how differently? This study focused to address this gap and identify the psychosocial correlates of stress and reactions to stressors of both American and international students.

The need for a study was greatly felt as many issues as possible of international students need to be further researched. The current study is different from previous studies since it seeks to examine stress among international students contrasting them with American students while examining some moderating variables such as general health and social support. There is an ever-growing number of international students, especially from India and China, attending schools in the United States, Australia, and the United Kingdom. An important concern of the universities and colleges is how to create and promote a congenial environment for international students. Toward this goal, the current study contributes to a deeper understanding of underlying issues of international students in relation to American/domestic students. Increased understanding of the issues could lead to developing appropriate measures and services for international students. The operational definition of stress for this research "is any sort of uneasiness and difficulties experienced by a student in social and psychological sphere of life due to college study."

The current study collected data from 95 international students (38 men and 57 women) using Gadzella's Student-Life Stress Inventory (SLSI, 1991). The SLSI was created based on Morris's (1990) model of stressors and reactions consisting of 9 sections and 51 items designed to measure stress among international students. Morris' model describes five types of stressors to include frustrations, conflicts, pressures, changes, and self-imposed stressors, and four clusters of reactions including physiological, emotional, behavioral, and cognitive reactions. Besides stress, other variables included general health, social provisions (known as social support), and social desirability. Standardized scales were used to measure social provisions (Russell and Cutrona, 1984), social desirability (Marlowe and Crowne, 1992), general health (Goldberg \& Hiller, 1979), Goldberg and Blackwell (1970), and student life stress inventory [SLSI] (Gadzella, 1991). Permission to use the scales from the authors for each scale was obtained before using the instrument for data collection. The scales were tested on the small group of 10 students before being administered to the entire study sample.

\subsection{American and International Students by Demographics}

Previous research demonstrated relationships between a few demographic variables and stress among students. Women's 
reaction to stress was different compared to men's reactions to stress. Moreover, women rated negative events more seriously than men. Past research revealed lower levels of social support and higher levels of life stress contributed to academic stressors in students.

The demographic details such as age, gender, student status, and current academic performance of the student sample were collected as a part of this research study. Around $88.5 \%$ of American students and $95.6 \%$ of international students were between the ages of 18 to 35 years. Over the age of 35 years, $11.5 \%$ of American students and $4.4 \%$ of international students were enrolled. The sample consisted of both male and female students, with $23.66 \%$ of American male students and $76.33 \%$ American female students. The sample consisted of $65.55 \%$ of International male students and $34.44 \%$ of them were international female students.

Most international students were from India followed by China, Bangladesh, Pakistan, and Japan. About 98 percent of American students and 22.2 percent of international students were enrolled in undergraduate programs, while 2.3 percent of American students and 77.8 percent of international students were enrolled in graduate programs. Another major difference in the study was that nearly $70 \%$ of American students were studying social sciences, compared to $70 \%$ of international students studying engineering, computer science, and business disciplines.

The current academic performance of American students and international students in an excellent category is $25.56 \%$ and $36.66 \%$ respectively; in the good category are $83.33 \%$ and $47.78 \%$ respectively, in the average category are $33.33 \%$ and $12.22 \%$; and in the fair category are $3.33 \%$ and $3.33 \%$ respectively. Around $40 \%$ of international students received fellowships, scholarships, and fee waivers from the university, $8.88 \%$ of graduate students had part-time jobs as graduate assistants, $30.53 \%$ of American students received support from the university, and $18.32 \%$ had part-time jobs as they were in the undergraduate program. A higher percent of international students had financial support from attending school than American students.

This current research revealed that American students and international students showed significant differences in the type of family support and the period of stay in the United States. Around 40.09\% of the sample consisted of American students and $24.44 \%$ of international students received family support. No significant differences were found between the socioeconomic status of American and International students since 80 to $85 \%$ of the respondents from both groups belonged to the middle class. And $16.93 \%$ were from the upper class and $18.33 \%$ belonged to the lower socioeconomic stratum.

\section{General Health}

College students whose lives were impacted by stressful life events in their families reported higher levels of anxiety, depression, and bodily pains, worse health perceptions as well as cognitive and social functioning (Damush, Hays, \& DiMatteo, 1997). Students who experienced sexual distress reported greater depression, less positive feelings, and a lower sense of belonging (Damush, Hays, \& DiMatteo, 1997). It was observed that they tend to seek refuge and a sense of belonging with their peers. Individuals who were affected by family life-events showed greater dysphoria and poor general health (Damush, Hays, \& DiMatteo, 1997).

Bradley (2000) study found that international students experienced a variety of economic, social, and academic pressures compared to American students in varying degrees. Some students encountered financial difficulties, and, in extreme cases, they were forced to return home. International students experienced culture shock and felt excluded from the mainstream students' population. Further, the findings indicated some international students had a difficulty in making friends, which led to interpersonal tensions. The study reported an increasing number of international students suffered mental health problems due to difficulties in adaptation to a new culture and academic environment. There was a possibility that cultural differences would mask such symptoms and create a false state of wellbeing. In Hirsch and Ellis's (1996) study, high levels of stress and other health habits were related.

\section{Social Provisions}

Studies of Boyer and Sedlack (1988) and Pederson (1991) provided solid evidence that international students had good academic skills but tended to face more problems than American students owing to fewer resources available at their disposal. Other studies by (Newcomb, Huba, and Bentler, 1981; Sherman and walls, 1995; Siegel and Brown, 1988;) on adolescents also conveyed similar sort of results on stressful life events and depression. Social support was found to be a moderator in framing the perception of stressful events and health-related quality of life.

The study by Hackett, Betz, Casas, and Singh (1992) sought to predict students' academic achievement by purporting the notion that a low level of stress was correlated with academic self-efficacy. It also delineated academic performance was not related to social support as the variables namely personal interests, positive outcome expectations, and faculty encouragement were negatively related to it. Overall, the findings showed that academic self-efficacy could mediate the effects of prior academic achievement, stress and strain, and coping behavior as well as academic achievements. 


\section{Social Desirability}

In one research conducted on international students, it was found that they felt pressured to achieve higher academic success and top grades or ranks (Mori, 2000; Zwingmann \& Gunn, 1983). The study further pointed out that international students experienced problems in the domain of interpersonal relations. Furthermore, they were not comfortable even expressing their problems for a variety of reasons. Bradley (2000) revealed it was a great achievement for foreign students to come abroad for higher education but later experienced shock, depression, and disappointment.

Lewthwaite's (1996) study on international students in New Zealand revealed that many international students had trouble in meeting the people except other than study-related purposes. New Zealanders, though friendly at all levels, were found it difficult to maintain relationships. The study found that some students felt the university professors were not approachable due to personal or cultural inhibitions.

\section{Stress among International and American students}

Both American and international student groups experienced varying degrees of stress which have the potential to affect their well-being, health, and mental health. The differences in stressors and reactions between international and American students are detailed in Table 1.

\subsection{Difference between American and International Students}

Table 1. Differences between American and International Students by Sub-scales of Stress

\begin{tabular}{|c|c|c|c|c|c|c|}
\hline Stress dimension & Students & Number & Mean & Standard deviation & $\mathrm{t}=$ value $\mathrm{df}=219$ & $\mathrm{P}<0.05$ \\
\hline \multicolumn{7}{|c|}{ I. Stressors } \\
\hline \multirow[t]{2}{*}{ a. Frustrations } & American & 131 & 16.75 & 4.03 & \multirow[t]{2}{*}{$\mathrm{t}=1.48$} & \multirow[t]{2}{*}{ Not significant } \\
\hline & International & 90 & 15.90 & 4.44 & & \\
\hline \multirow[t]{2}{*}{ b. Pressures } & American & 131 & 15.14 & 3.89 & \multirow[t]{2}{*}{$\mathrm{t}=2.75$} & \multirow[t]{2}{*}{ Significant } \\
\hline & International & 90 & 13.63 & 4.16 & & \\
\hline \multirow[t]{2}{*}{ c. Conflicts } & American & 131 & 6.72 & 2.09 & \multirow[t]{2}{*}{$\mathrm{t}=-1.30$} & \multirow[t]{2}{*}{ Not significant } \\
\hline & International & 90 & 7.11 & 2.34 & & \\
\hline \multirow[t]{2}{*}{ d. Changes } & American & 131 & 7.11 & 2.68 & \multirow[t]{2}{*}{$t=0.525$} & \multirow[t]{2}{*}{ Not significan } \\
\hline & International & 90 & 6.92 & 2.65 & & \\
\hline \multirow[t]{2}{*}{ e. Self-imposed } & American & 131 & 20.05 & 4.24 & \multirow[t]{2}{*}{$t=-0.04$} & \multirow[t]{2}{*}{ Not significant } \\
\hline & International & 90 & 20.07 & 4.59 & & \\
\hline \multicolumn{7}{|c|}{ II. Reactions to stressful events } \\
\hline \multirow[t]{2}{*}{ a. Physical reactions } & American & 131 & 30.41 & 9.89 & $\mathrm{t}=4.11$ & Significant \\
\hline & International & 90 & 25.01 & 9.12 & & \\
\hline \multirow[t]{2}{*}{ b. Emotional reactions } & American & 131 & 11.25 & 4.09 & $t=3.64$ & Significant \\
\hline & International & 90 & 9.30 & 3.67 & & \\
\hline \multirow[t]{2}{*}{ c. Behavioral reactions } & American & 131 & 16.90 & 5.30 & $\mathrm{t}=3.89$ & Significant \\
\hline & International & 90 & 14.12 & 5.10 & & \\
\hline \multirow[t]{2}{*}{ d. Cognitive reactions } & American & 131 & 5.74 & 2.17 & $\mathrm{t}=-0.32$ & Not significant \\
\hline & International & 90 & 5.84 & 2.23 & & \\
\hline
\end{tabular}

It is evident that International and American students did not show significant differences on many dimensions of stressors except on conflicts. The mean score of conflicts was significantly higher for international students. In terms of self-imposed stressors, there were no differences between American and International students. Regarding the reactions by international and American students to stressful situations, there were significant differences in physiological, emotional, and behavioral realms. On cognitive reactions, there were no significant differences in the means between International and American students, although, the international students had higher reactions (greater mean value).

\section{Stress Levels}

Gadzella's SLSI has been designed to measure academic stressors and reactions to stressors among college students. The scale is helpful to determine the levels of stress based on the scores obtained by international and American students. The scores are used to categorize three levels of stress - mild, moderate, and severe among the students. Table 2 depicts the levels of stress among the students in American and international students. 
10.1 Level of Stress in International and American

Table 2. Levels of Stress in International and American students

\begin{tabular}{|l|l|l|l|l|}
\hline Stress levels & Score ranges & American students $(\mathrm{N}=131)$ & International students $(\mathrm{N}=90)$ & Total \\
\hline Less than mild & $51-89$ & $9(6.8 \%)$ & $11(12.22 \%)$ & $20(9.04 \%)$ \\
\hline Mild stress & $90-121$ & $46(35.11 \%)$ & $37(41.1 \%)$ & $83(37.5 \%)$ \\
\hline Moderate stress & $122-158$ & $60(45.8)$ & $37(41.1 \%)$ & $97(43.8 \%)$ \\
\hline Severe stress & $159-123$ & $16(12.2 \%)$ & $5(5.5 \%)$ & $21(9.5 \%)$ \\
\hline Total & $131(100 \%)$ & 90 & $221(100 \%)$ \\
\hline \multicolumn{4}{|c|}{ Chi Square= $101.90 ; \mathrm{df}=99 ; \mathrm{p}=0.05$ Not significant } \\
\hline
\end{tabular}

The analysis points out the statistically significant associations among the stress levels between American and international students. However, stress was experienced by both American and international students. Nearly 58\% of American students and $47 \%$ of international students experienced moderate to severe levels of stress that called for some interventions and services for them. About $10 \%$ of students experienced severe levels of stress, while a higher proportion of American students experienced greater stress. It is quite possible that some of the international students had difficulties in dealing with stress in a new environment.

\subsection{Differences in General Health Symptoms in American and International Students}

Table 3. Different General Health Symptoms in American and International students

\begin{tabular}{|l|l|l|l|l|}
\hline \multirow{2}{*}{ General Health symptoms } & American students & \multicolumn{3}{l|}{ International students } \\
\cline { 2 - 5 } & Mean & Std deviation & Mean & Std. deviation \\
\hline Somatic symptoms (7 items) & 14.87 & 3.44 & 13.30 & 3.07 \\
\hline Anxiety \& insomnia (7 items) & 15.58 & 4.21 & 14.32 & 3.76 \\
\hline Severe depression (7 items) & 14.15 & 2.82 & 12.98 & 3.53 \\
\hline Social dysfunction (7 items) & 9.52 & 3.74 & 9.80 & 3.71 \\
\hline
\end{tabular}

It is evident from the above table that international students obtained a higher social dysfunction with a higher mean score, while on other dimensions, American students had higher symptoms. Both international and American students had scored higher on anxiety and insomnia compared to other manifestations of health symptoms due to stress (current or accumulated), while the lowest scores were found on the dimension of social dysfunction among both international and American students.

\subsection{International and American students on Four key Variables}

International and American students were expected to have significant differences on independent variables of student's life stress and dependent variables such as general health, social support, and social desirability. The t-test for equality of means between independent samples was applied to find out significant differences between American and international students on each of the test variables in the current study. Table 4 provides differences between international and American students with regard to the key variables.

10.4 International and American students on Four key Variables

Table 4. American and International Students by test Variable Statistics

\begin{tabular}{|c|c|c|c|c|c|c|}
\hline Test Variable & $\begin{array}{c}\text { American/International } \\
\text { Students }\end{array}$ & $\mathbf{N}$ & Mean & Std. dev. & $\mathbf{t}^{*}$ & Significance** \\
\hline \multirow{2}{*}{$\begin{array}{lll}\begin{array}{l}\text { Students' life } \\
\text { inventory }\end{array} & & \\
\end{array}$} & Domestic students & 131 & 130.11 & 28.31 & \multirow[t]{2}{*}{3.17} & \multirow[t]{2}{*}{0.002} \\
\hline & International students & 90 & 117.92 & 27.76 & & \\
\hline \multirow[t]{2}{*}{ General health scores } & American students & 131 & 54.14 & 11.34 & \multirow[t]{2}{*}{2.42} & \multirow[t]{2}{*}{0.016} \\
\hline & International students & 90 & 50.41 & 11.13 & & \\
\hline \multirow[t]{2}{*}{ Social provisions } & American students & 131 & 59.38 & 3.47 & \multirow[t]{2}{*}{0.28} & \multirow[t]{2}{*}{0.779} \\
\hline & International students & 90 & 59.24 & 4.16 & & \\
\hline \multirow[t]{2}{*}{ Social Desirability } & American students & 131 & 14.08 & 2.77 & \multirow[t]{2}{*}{0.707} & \multirow[t]{2}{*}{0.480} \\
\hline & International students & 90 & 13.81 & 2.77 & & \\
\hline
\end{tabular}

It is evident from the table that international students were significantly different in stress and general health, while on social support and social desirability they did not differ at a statistically significant level. American students experienced higher levels of stress as reflected by the mean score of 131 against international students' mean score of 118 . On general health, American students had a higher mean (mean=54) than international students (mean=50). On social support, both groups had equal means and with regards to social desirability mean scores of the two groups differed slightly. 


\subsection{Inter-Correlations between Test Variables}

Based on previous research, the research hypothesis proposed that student life stress, general health, social support, and social desirability would be correlated, hence, inter-correlations between the key variables of research were tested. And Table 5 presents the coefficients of inter-correlation between stress, general health, social support, and social desirability

10.6 Inter-Correlation Matrix of Dependent and Independent variables

Table 5. Inter-Correlation Matrix of Dependent and Independent variables

\begin{tabular}{l|l|l|l|l|}
\hline \multicolumn{1}{|c|}{ Variables } & \multicolumn{1}{c|}{ SLS Inventory } & General Health & \multicolumn{1}{c|}{ Social Provisions } & Social Desirability \\
\hline SLS Inventory & 1 & & & \\
\hline General Health & $0.579^{* *}$ & 1 & & \\
\hline Social Provisions & $0.182^{* *}$ & $0.114^{*}$ & 1 & 1 \\
\hline Social Desirability & -0.139 & 0.107 & 0.024 & 1 \\
\hline ** Correlation is significant at the 0.01 level (2-tailed). \\
* Correlation is significant at the 0.05 level (2-tailed). \\
\hline
\end{tabular}

The table shows that student life stress had a high positive correlation $(\mathrm{r}=0.57)$ with general health which is a statistically significant and low positive correlation $(\mathrm{r}=0.18)$ with social provisions at 0.01 level of significance. However, stress was found to have a low negative correlation with social desirability. The hypothesis relating to correlations between key variables was proved in the sense that all independent variables had statistically significant correlations with student life stress. The unexpected result was that social desirability had a negative correlation with student life stress.

\subsection{Predicting Stress in International and American Students}

One of the hypotheses seeks to examine how independent variables serve as predictors of stress. To establish these hypotheses, predictors of regression analysis was done, and the results are presented below.

Table 6. Predictors of Stress: Regression Analysis

\begin{tabular}{|l|c|c|c|c|}
\hline \multicolumn{1}{|c|}{ Model } & R Square & R square change & Degrees of freedom & Significance (p) \\
\hline General Health & 0.335 & 0.335 & 219 & 0.000 \\
\hline General health \& Social Provisions & 0.349 & 0.014 & 218 & 0.034 \\
\hline
\end{tabular}

It is evident from the analysis that two factors emerged as predictors of student life stress. The predictors were general health, which predicted $33 \%$ of the variance in student life stress, while social support accounted for $1 \%$ of the variance. The two variables together accounted for $35 \%$ of the variance, which is a quite significant explanation for this research. In other words, every unit increases in stress could be explained up to $35 \%$ with general health and social support.

\section{Causal Model of Stress}

The following causal model of stress, thus, emerges based on the current study research in figure 1

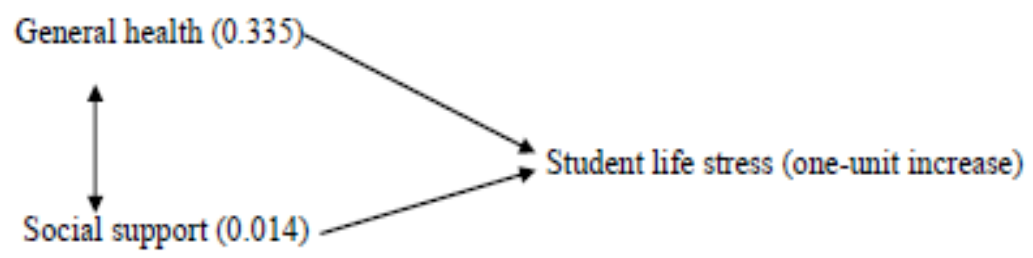

Figure 1. A causal model of stress

The model implies that stress among students can be effectively moderated or reduced by positively reinforcing general health and social support for international students. This model could be tried even for American students because the study discovered higher levels of stress in American students as well.

\section{Results Relative to Hypotheses}

The international students (mean=118; standard deviation=27.76) were found to have less stress compared to American students. The mean value of American students on student-life stress inventory was higher (Mean=130.11; std dev=28.31). Although international students did not show higher stress than American students in this study, it did provide evidence that they experienced significantly higher levels of stress, which is above the levels of stress threshold suggested by the author of the scale for interventions. General health emerged as the leading predictor of student-life stress with 33\%, while 
social provisions turned out to be the second predictor as both variables together explained $35 \%$ of the variance in the study.

As regards student-life stress, female students (means=130.71; std. dv. $=30.43$ ) had statistically significant student-life stress when compared to males (mean=117.78; std dev=23.78) regardless of American or international student status $(\mathrm{F}=$ 12.75 at the 0.000 level). International and American students showed statistically significant differences in general health which was the independent variable. Significant differences were not found in the other two independent variables.

The research concluded that the dependent variable significantly correlated with two of the independent variables general health and social provisions (support), while another independent variable, social desirability, did not show any significant relationship in bivariate and multivariate analyses. About 35\% (R Square $=0.349$ at 0.03 level) of student stress is predictable with general health and social provisions. Social desirability showed a negative relationship with the dependent variable but did not figure in the regression analysis.

\section{Discussion}

Previous research revealed that international students did not feel comfortable expressing stress like their counterparts in the United States. Lack of expressiveness among international students was attributed to cultural factors, especially among Asian students. Since a majority of international students were male, gender stereotypes might have moderated the levels of perceived stress. American students who were mostly women might have an impact on the perceptions of stress including age, undergraduate/graduate status, academic performance, off-campus part-time jobs that most undergraduates do. The economic recession in the United States and the high rate (7/8 \%) of unemployment (national average around 5\%) in the county where the university is located might be other reasons. There was a significant proportion of students among the American student population who are non-traditional students. These non-traditional students had jobs and families on one hand and college work on the other, potential conflicts and higher demands placed on their time. Since this scale was designed to measure stressors and reactions to stressors among college students. The study concluded, sizeable groups of international and American students experienced stress. To address this problem among the international students, there is a need for more student services for international students and programs to acclimatize them to the new environment. Currently, international students related to student organizations and local Indian and Chinese communities the moderating effects of these factors need to be studied.

Earlier a study (Shenoy, 2000) concluded that there was no stress among international students, while this research study found stress among international students although it is less than what American students have. This needs to be further researched into controlling some variables and adopting a more advanced sampling procedure.

\section{Limitations of the Study and Future Directions}

This study could not get a sample of international students in the undergraduate class as international students usually come for graduate education. In contrast, most American students' samples were from the undergraduate class. American students had older compared to international students based on the mean ages of both groups. This was another limitation of the study. Most international students were from India and China and a few students from other countries. The current study used quota sampling due to university restrictive policies and not a fully random sampling method which is viewed as one big limitation of the study. The study made use of self-reports, and this might have impacted the students' responses. Hence, there is a limitation on the generalizability of the results of this research.

\section{Implications for Future Research}

International students did not show stress at a level the American students had in this study. This needs to be investigated by future studies from multiple angles. Recommending for future studies to use fully random sampling to ensure representation from international students from different countries. This would enable us to study the difference among the various international students. The group housing options available for international students appeared to have created avenues for peer relationships that met the emotional needs of new students. This aspect is also recommended for consideration in future research.

Shenoy (2000) concluded that there was no stress among international students. However, this study found higher levels of stress among international students although it is less compared to the American students. This remains a significant question to future researchers to build the knowledge on stress research pertaining to international students.

\section{Conclusions}

Stress is an important concern among college students. This research study offered theoretical and practical knowledge about the levels of academic stress and reactions to stressors. Moreover, the study identified the predictors of stress among international students in comparison to American students. This study found increased levels of stress present among international students, yet the amount of stress was less in comparison with American students. 
Two factors emerged as predictors of student's life stress namely, general health and social support, which contributed about $33 \%$ and $2 \%$ of the variance respectively to the independent variable - student life stress. The two variables together accounted for $35 \%$ of the variance, which is a quite significant reason for students' stress in college among international and American students.

Future researchers should expand the findings of current study on international students. A mental health professional must formulate culturally sensitive interventions to help college students in dealing with stress and enabling them to overcome. Institutions of higher education should develop more services for international students. In addition, gender-specific and culturally sensitive interventions must be provided as female students perceive stress differently than male students.

\section{Acknowledgments}

I express my gratitude to my Ph.D. supervisors Dr. B.C. Muthayya, Osmania University, India \& Dr. Terry, C. Tollar for supervision and data collection University of Toledo, United States.

\section{References}

Aneshensel, C. S. (1988). Disjunctures between public health and medical models. A paper presented at the meetings of the American Public Health Association, Boston.

Berry, J. W. (1985). Psychological adaptation of foreign students in Canada. In R. Samuda \& A. Wolfgang (Eds.), Intercultural counseling and assessment: Global perspectives (pp. 235-248). Lewiston, NY: Hogrefe.

Boyer, S. D., \& Sedlacek., W. E. (1988). Non-cognitive prediction of academic success for international students: A longitudinal study. Journal of College Student Development, 29, 218-223.

Bradely, G. (2000). Responding effectively to the mental health needs of international students. Higher Education, 39, 417-433. https://doi.org/10.1023/A:1003938714191

Cheng, D., Leong, F. T. L., \& Geist, R. (1993). Cultural differences in psychological distress between Asian and Caucasian American college students. Journal of Multicultural Counselling and Development, 21, 182-190. https://doi.org/10.1002/j.2161-1912.1993.tb00598.x

Crowne, D.P. \& Marlowe, D. (1960). A new scale of social desirability independent of psychopathology. Journal of Consulting Psychology, 24(4), 349-354. https://doi.org/10.1037/h0047358

Damush, T. M., Hays, R. D., \& Dimaitteo, M. R. (1997). Stressful life events and health-related quality of life in college students. Journal of College Student Development; Mar/Apr 1997; 38(2), 181-190.

Edwards, K. J., Hershberger, P. J., Russell, R. K., \& Market, R. J. (2001). Stress, negative social exchange, and health symptoms in university students. Journal of American College Health, 50, 75-79. https://doi.org/10.1080/07448480109596010

Essandoh, P. K. (1995). Counseling issues with African college students. The Counseling348-360 Psychologist, 23, 348-360. https://doi.org/10.1177/0011000095232009

Gadzella, B. M. (1991). Student-Life Stress Inventory: Identification of and Reactions to Stressors. Psychological Reports, 74, 395-402. https://doi.org/10.2466/pr0.1994.74.2.395

Goldberg, D. P., \& Hiller, V. F. (1979). A scaled version of the general health questionnaire. Psychological Medicine, 9 , 139-145. https://doi.org/10.1017/S0033291700021644

Goldberg, D. P., \& Blackwell, B. (1970). Psychiatric illness in general practice. A detailed study using a new method of case identification. British medical journal, 1(5707), 439-43. https://doi.org/10.1136/bmj.2.5707.439

Hackett, G., Betz, N. E., Casas, J. M., \& Singh, I. A. R. (1992). Gender, ethnicity, and social-cognitive factors predicting the academic achievement of students in engineering. Journal of Counseling Psychology, 39(4), 527-538. https://doi.org/10.1037/0022-0167.39.4.527

Harris, H. W. (1972). The relationship of life changes to academic performance among selected college freshmen at varying levels of college readiness in Unpublished Doctoral dissertation.

Hirsch, J. K., \& Ellis, J. B. (1996). Differences in life stress and reasons for living among college suicide ideators and non-ideators. College Student Journal, 30(3), 377-386.

Kaczmarek, P. G., Matlock, G., Merta, R., Ames, \& Ross, M. (1994). An assessment of international college student adjustment. International Journal for the advancement of Counselling, December 1994, 17(4), 241-247. https://doi.org/10.1007/BF01407740 
Lazarus, R. S. (1966). Psychological stress and the coping process. New York: Mc Graw Hill.

Lazarus, R. S., \& Folkman, S. (1994). Stress, appraising and coping. New York: Springer.

Leong, F., Mallinckrodt, B., \& Kralj, M. (1990). Cross-cultural variations in stress and adjustment among Asian and Caucasian graduate students. Journal of Multicultural Counseling and Development, 18(1), 19-28. https://doi.org/10.1002/j.2161-1912.1990.tb00433.x

Lewthwaite, M. (1996). A study of international students' perspectives on cross-cultural adaptation. International Journal for the Advancement of Counseling, 19(92), 167-185. https://doi.org/10.1007/BF00114787

Mc Murtie, B. (2001). Foreign enrollments grow in the U.S. but so do competition from other nations. The Chronicle of Higher Education, November 16, p.A45.

Misra, R., McKean, M., West, S., \& Russo, T. (2000). Academic stress of college students: Comparison of student and faculty perceptions. College Student Journal, 34, 236-245.

Morris, C. G. (1990). Contemporary psychology and effective behavior (7th ed.). Glenview, IL: Scott, Foresman.

Morris, S. C. (2000). Addressing the mental health concerns of international students. Journal of Counseling and Development, 78, 137-144. https://doi.org/10.1002/j.1556-6676.2000.tb02571.x

Newcomb, M. D., Huba, G. J., \& Bentler, D. M. (1981). A multidimensional assessment of stressful life events among adolescents: Derivation and correlates. Journal of Health and Social Behavior, 22, 400-415. https://doi.org/10.2307/2136681

Olberg, K. (1960) culture Shock: Adjustment to New Cultural Environments. Practical Anthropology, 7, 177-182. https://doi.org/10.1177/009182966000700405

Pearlin, L. I. (1999). Stress and mental health: A conceptual overview. In T. L. Scheid (Ed.), 161-175). New York: Cambridge University Press.

Pederson, P. B. (1991). Counseling international students. The Counseling Psychologist, 19, 10-58. https://doi.org/10.1177/0011000091191002

Rajendran, R., \& Kaliappan, K. V. (1991). A factorial study of sources of student academic stress. Journal of psychological Researchers, 35(2), 53- 57.

Rao, K., Moudud, Z., \& Subbakrishna, D. K. (2000). On appraisal of stress and coping behavior in college students. Journal of the Indian Academy of Applied Psychology, 26(1-2), 5-13.

Russell, D., \& Cutrona, C. E. (1987). (1984 or 1987) The provisions of social relationships and adaptation to stress. Advances in Personal Relationships, 1, 37-67.

Reynolds, W. M. (1982). Development of reliable and valid short forms of the Marlowe-Crowne Social Desirability Scale. Journal of Clinical Psychology, 38(1), 119-125. https://doi.org/10.1002/1097-4679(198201)38:1<119::AID-JCLP2270380118>3.0.CO;2-I

Reifman, A., \& Dunkel-Schetter, C. (1990). Stress, structural social support, and well-being in university students. Journal of American College Health, 38(6), 271-277.

Strahan, R., \& Gerbasi, K. C. (1972). Short, homogeneous versions of the Marlowe-Crowne Social Desirability Scale. Journal of Clinical Psychology, 28(2), 191-193.

https://doi.org/10.1002/1097-4679(197204)28:2<191::AID-JCLP2270280220>3.0.CO;2-G

Sarason, I. G., Pierce, G. R., \& Sarason, B. R. (1994). General and specific perceptions of social support. In R.W. Avison \& H.I. Gollib (Eds.), Stress and mental health: Contemporary issues and prospects for the future. New York \& London: Plenum Press. pp. 151-173. https://doi.org/10.1007/978-1-4899-1106-3_6

Shenoy, U. A. (2000). College- stress and symptom expression in international students: A comparative study. Unpublished doctoral dissertation. Blacksburg, Virginia: Virginia Institute \& State University.

Sherman, A. G., \& Walls, J. W. (1995). Gender differences in the relationship of moderator variables to stress and symptoms. Psychology and Health, 10, 321-331. https://doi.org/10.1080/08870449508400246

Siegel, J. M., \& Brown, J. D. (1988). A prospective study of stressful circumstances, illness symptoms, and depressed mood among adolescents. Developmental Psychology, 24, 715-721. https://doi.org/10.1037/0012-1649.24.5.715

Tandon, S. (1986). Development of measures of stress tolerance. An unpublished Ph.D. thesis. Allahabad: University of Allahabad.

Weiss, R. (1974). The Provisions of Social Relationships. In Rubin, Z., Ed., Doing unto Others, Prentice-Hall, Englewood 
Cliffs, 17-26.

Ying, Y. W., Lee, P. A., \& Tsai, J. L. (2004). Inventory of college challenges for ethnic minority students: Psychometric properties of a new instrument in Chinese Americans. Cultural Diversity and Ethnic Minority Psychology, 10(4), 351-364. https://doi.org/10.1037/1099-9809.10.4.351

Zaleski, E. H., Levey-Thors, C., \& Schiaffino, K. M. (1999). Coping mechanisms, stress, social support, and health problems in college students. Applied Developmental Science, 2, 127-137. https://doi.org/10.1207/s1532480xads0203_2

Zook A., \& Sipps, G. J. (1985). Cross-validation of a short form of the Marlowe-Crown social desirability scale. J. Clin. Psychol,. 41, 236-238.

Zwingmann, C. A., \& Gunn, A. G. (1983). Uprooting and health: Psychosocial problems of students from abroad. Geneva: Division of Mental health, World Health Organization.

\section{Copyrights}

Copyright for this article is retained by the author(s), with first publication rights granted to the journal.

This is an open-access article distributed under the terms and conditions of the Creative Commons Attribution License which permits unrestricted use, distribution, and reproduction in any medium provided the original work is properly cited. 